\title{
Resident wellness: institutional trends over 10 years since 2003
}

\author{
Dongseok Choi ${ }^{1,2}$ \\ Andrea Cedfeldt ${ }^{3,4}$ \\ Christine Flores ${ }^{5}$ \\ Kimberly Irish ${ }^{3}$ \\ Patrick Brunett ${ }^{3,6}$ \\ Donald Girard ${ }^{3,4}$ \\ 'OHSU-PSU School of Public \\ Health, Oregon Health \& Science \\ University, Portland, OR, USA; \\ ${ }^{2} S c h o o l$ of Dentistry, Kyung Hee \\ University, Seoul, Korea; ${ }^{3}$ Division \\ of Graduate Medical Education, \\ ${ }^{4}$ Department of Medicine, ${ }^{5}$ Division of \\ Continuing Professional Development, \\ ${ }^{6}$ Department of Emergency Medicine, \\ Oregon Health \& Science University, \\ Portland, OR, USA
}

Correspondence: Dongseok Choi Oregon Health \& Science University, 3181 SW Sam Jackson Park Road,

Portland, OR 97239, USA

$\mathrm{Tel}+\mathrm{I} 5034945336$

Fax + I 503494498 I

Email choid@ohsu.edu
This article was published in the following Dove Press journal:

Advances in Medical Education and Practice

26 July 2017

Number of times this article has been viewed

Background: The surveys in this study were carried out at the Graduate Medical Education Division at Oregon Health \& Science University (OHSU). OHSU implemented two significant wellness initiatives: a wellness program in 2004, and a policy allowing 4 half-days off each academic year to pursue personal or family health care needs in 2010 . This study provides a secondary data analysis of five cross-sectional surveys of career satisfaction of resident and fellow trainees.

Methods: All trainees were surveyed five times over a 10-year period using anonymous, crosssectional web-based survey instruments. Surveys included questions about career satisfaction, perceived stress, sleep hours, burnout, and related factors.

Results: This represents 10 years of accumulated responses from over 2,200 residents with results showing continual improvement in their career satisfaction. Response rates ranged from $56 \%$ to $72 \%$. During the study period, there was a significant positive change in overall resident career satisfaction, with little change in factors traditionally considered to be predictive of overall career satisfaction such as sleep hours or perceived stress level. In addition, our data support that availability of time for personal tasks could positively impact the overall training experience.

Conclusion: We postulate that the improvements in satisfaction relate to two major institutional innovations designed to promote resident wellness.

Keywords: satisfaction, burnout, graduate medical education, personal time-off

\section{Introduction}

Studies report that more than three quarters of residents meet criteria for burnout and have expressed career dissatisfaction. ${ }^{1-3}$ These alarming data sound a clear call for effective interventions (both personal and institutional) to prevent burnout and promote resilience and wellness among physicians-in-training.

There are numerous challenges in promoting physician well-being during residency training. Little research has been published about institutional policies directed at helping residents achieve the positive aspects of wellness. ${ }^{4}$ Our paper adds to this limited literature by providing a long-term evaluation of institutional interventions aimed at enhancing resident wellness.

The Division of Graduate Medical Education (GME) at Oregon Health \& Science University (OHSU) in Portland, Oregon, USA has surveyed residents and fellows about their career satisfaction for nearly 30 years and published those results. ${ }^{5-14}$ As previously reported, residents in our institution have been generally satisfied with their career choices. In an ongoing effort to establish innovative programs that further 
enhance trainee satisfaction and wellness, we implemented two major institutional initiatives. The first was a resident wellness program (RWP) that began in July 2004. ${ }^{15}$ Staffed by a psychiatrist and clinical psychologists, all residents and fellows have access to confidential individual or family counseling. RWP staff also provide group training in topics related to wellness, resilience, and burnout prevention. The second was the implementation of a GME-wide policy requiring all training programs to assign residents 4 half-days off per academic year to pursue personal or family health care needs. This policy was implemented in July 2010. In order to evaluate the impact of these institution-wide changes in resident career satisfaction, we have analyzed trends in our survey data over a 10-year time frame.

During the study period, there were two major changes to GME in the US implemented by the Accreditation Council for GME (ACGME). One significant change in 2003 was restricting duty hours per week to 80 hours for all residents in the US and in 2011 the duty period for the first year trainees was restricted to 16 hours in duration. We have also evaluated these findings in the context of the ACGME duty hour changes implemented in 2003 and modified in 2011.

\section{Methods}

OHSU is a large urban, tertiary care academic health center located in Portland, Oregon. This is a secondary data analysis of cross-sectional surveys of all resident and fellow trainees at OHSU over the 10-year period in 2003, 2005, 2008, 2011, and 2013. For each survey, all residents and fellows in OHSU's ACGME accredited residency programs were surveyed. All surveys were anonymous and web-based, therefore, the OHSU Institutional Review Board did not require that written informed consent be obtained from the participants. Although there were some minor differences among surveys, all were distributed and collected during January of each study period. Each survey included the same key questions about 1) career choice satisfaction and perceived stress, 2) work and sleep hours, and 3) personal time-off. In the 2011 and 2013 surveys, one question about burnout ${ }^{16}$ was added.
The Maslach Burnout Inventory ${ }^{17}$ was added in 2013. That survey questionnaire can be found in Appendix S1. This study was approved by the OHSU Institutional Review Board.

Statistical analyses included frequency tables and descriptive statistics. The chi-square test was used to compare responses among cohorts. A linear model was employed to analyze career choice satisfaction over survey years and by demographic factors. Since the 2008 survey, personal time availability (PTA) scores were calculated by averaging the responses to nine questions that used a 4-point Likert scale (Q51 in Appendix S1). ${ }^{12}$ A higher PTA score represents the ability for one to find time to meet personal needs more frequently (exercise, connecting with family and friends, etc). ${ }^{12}$ The chi-square test was used to compare satisfaction, stress, and burnout between residents with PTA scores above and those below the median for the entire group for each survey separately. A $p$-value $<0.05$ was considered statistically significant. All computations were performed using $R$ statistical language. ${ }^{18}$

\section{Results}

Table 1 summarizes the time period and response rates for each survey. Response rates ranged from $56 \%$ to $72 \%$. The demographics of the cohorts of all five surveys are shown in Table 2. The majority of residents were 26-35 years of age and White. During the study period, there were no notable changes in the distributions of gender, age, or race, but there were increasing proportions of residents in specialty training programs and in postgraduate training years (PGY) of $\geq 4$ years. The demographic characteristics of respondents in each survey did not differ significantly from those of the entire resident group in the survey year, suggesting the respondents were representative of all trainees in that survey year. ${ }^{10-12}$

Figure 1 displays the notable changes in trends of career satisfaction and other key measures across trainee programs. All five surveys show that trainees were generally satisfied with their career choices. Average scores for career satisfaction were relatively unchanged from 2003 through 2008: 3.85 (sample standard deviation [SD] =1.10)

Table I Response rates for surveys: overview

\begin{tabular}{|c|c|c|c|c|c|}
\hline Survey year & Start date (mm/dd/yyyy) & End date (mm/dd/yyyy) & Respondents (n) & Residents (n) & Response rate (\%) \\
\hline 2003 & $12 / 15 / 2002$ & $|/ 3| / 2003$ & 327 & 581 & 56 \\
\hline 2005 & $1 / 15 / 2005$ & $2 / 28 / 2005$ & 450 & 625 & 72 \\
\hline 2008 & $1 / 15 / 2008$ & $2 / 29 / 2008$ & 445 & 675 & 66 \\
\hline 2011 & $1 / 15 / 201 \mathrm{I}$ & $2 / 28 / 2011$ & 507 & 701 & 72 \\
\hline 2013 & $1 / 15 / 2013$ & $2 / 28 / 2013$ & 520 & 752 & 69 \\
\hline
\end{tabular}

Abbreviations: dd, day; mm, month; yyyy, year. 
Table 2 Characteristics of survey respondents

\begin{tabular}{|c|c|c|c|c|c|}
\hline \multirow[t]{2}{*}{ Characteristics } & \multicolumn{5}{|c|}{ Survey year } \\
\hline & 2003 & 2005 & 2008 & 2011 & 2013 \\
\hline Number of respondents & 327 & 450 & 445 & 507 & 520 \\
\hline \multicolumn{6}{|l|}{ Gender } \\
\hline Female (\%) & 48 & 49 & 46 & 51 & 50 \\
\hline Male $(\%)$ & 49 & 51 & 54 & 49 & 50 \\
\hline Unknown (\%) & 3 & 0 & 0 & 0 & 0 \\
\hline \multicolumn{6}{|l|}{ Age } \\
\hline $26-30(\%)$ & 41 & 42 & 38 & 32 & 36 \\
\hline $31-35(\%)$ & 35 & 43 & 45 & 50 & 48 \\
\hline $36-40(\%)$ & 9 & 10 & 11 & 10 & 10 \\
\hline $40+(\%)$ & 6 & 4 & 4 & 6 & 5 \\
\hline Unknown (\%) & 9 & 0 & 2 & 1 & 1 \\
\hline \multicolumn{6}{|l|}{ Race } \\
\hline White (\%) & 57 & 77 & 79 & 77 & 75 \\
\hline Others (\%) & 15 & 23 & 18 & 23 & 25 \\
\hline Unknown (\%) & 28 & 1 & 2 & 0 & 0 \\
\hline \multicolumn{6}{|l|}{ Specialty } \\
\hline Primary care (\%) & 34 & 30 & 29 & 25 & 25 \\
\hline Others (\%) & 66 & 70 & 71 & 75 & 75 \\
\hline \multicolumn{6}{|l|}{ Postgraduate training year } \\
\hline I (\%) & 26 & 24 & 21 & 14 & 21 \\
\hline $2(\%)$ & 25 & 25 & 24 & 22 & 20 \\
\hline $3(\%)$ & 23 & 22 & 22 & 22 & 18 \\
\hline $4+(\%)$ & 26 & 28 & 32 & 42 & $4 \mid$ \\
\hline Unknown (\%) & 0 & I & 0 & 0 & 0 \\
\hline
\end{tabular}

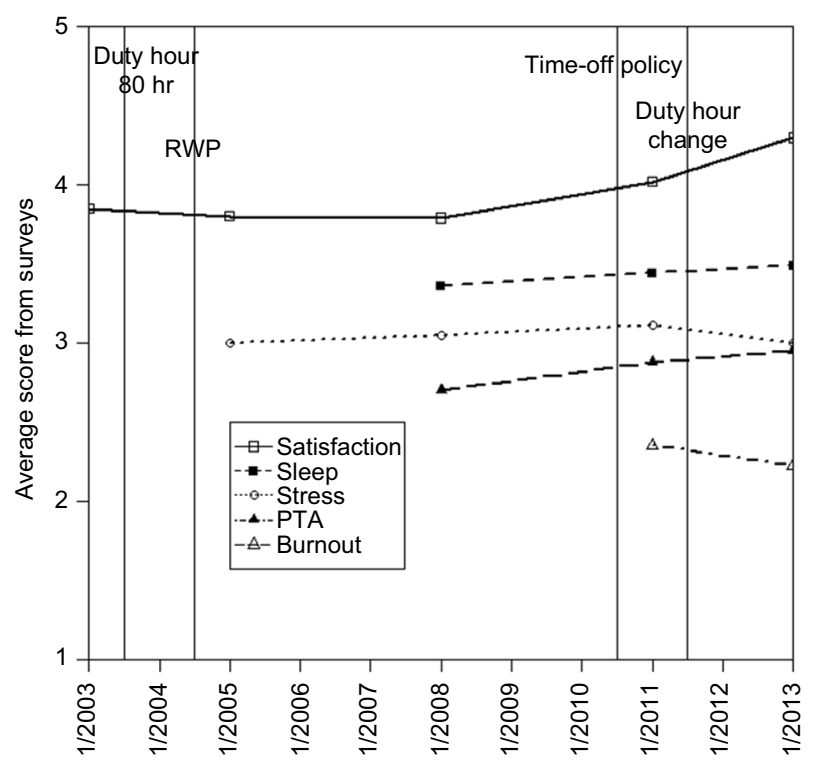

Figure I Trends in key outcome measures and major changes in training environment.

Notes: Sleep: I, <3 hours; 2, 3-4 hours; 3, 5-6 hours; 4, 7-8 hours; 5, 8+ hours. Dates shown as month/year, eg, I/2003 indicates January 2003. Some questions were added in later surveys.

Abbreviations: RWP, resident wellness program; PTA, personal time availability.

in $2003 ; 3.80(\mathrm{SD}=1.14)$ in $2005 ; 3.79(\mathrm{SD}=1.12)$ in 2008. However, there were significantly higher scores in satisfaction in the latter 2 survey years, 2011 and 2013: 4.02 ( $\mathrm{SD}=1.09$, chi-square test against 2008, $p=0.005$ ); and $4.30(\mathrm{SD}=0.84$, chi-square test against $2011, p<0.001)$, respectively. Perceived stress levels increased significantly in 2008 (mean $\pm \mathrm{SD}, 3.05 \pm 0.82$, chi-square test against 2005, $p=0.027)$ and $2011(3.11 \pm 0.80$, chi-square test against 2008, $p=0.028$ ), and then returned to the 2005 level

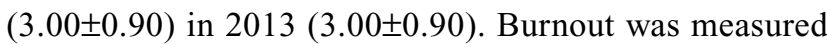
twice using a validated one item scale ${ }^{16}$ in $2011(2.35 \pm 0.75)$ and $2013(2.33 \pm 0.77)$. There was significantly less burnout reported in 2013 (chi-square test, $p=0.023$ ). Sleep hours did not show any significant change.

Table 3 summarizes survey-to-survey or within-survey subgroup analyses of career satisfaction by gender and PGY, respectively. With regard to gender, the within-survey analysis revealed that male trainees were more satisfied than female in 2003, 2008, and 2011. When the satisfaction scores of each gender group were compared survey-to-survey, the female group reported significantly higher career satisfaction scores than their female peers in 2011 (vs 2008; $p=0.028$, chi-square test) and 2013 (vs 2011; $p<0.001$, chi-square test). Similarly, PGY1 and PGY2 groups in 2013 survey reported significantly higher career satisfaction compared to their peers in 2011 ( $p=0.001$ for both, chi-square test). In contrast, 2013 within-survey analysis results did not show any differences in career satisfaction by gender or years in program. A multivariate analysis revealed that there were still significant differences in satisfaction across five surveys ( $F$-test, $p$-value $<0.001$ ) even after adjusted for gender, PGY, age, race (white vs others), and specialty (primary vs other specialty).

In a previous publication by our group,${ }^{12}$ residents with PTA scores above the median were significantly more satisfied with their careers, reported lower perceived stress, and more sleep hours than those with PTA scores below the median. Similar results were seen for respondents in the 2011 and 2013 surveys. In addition, residents with higher PTA scores tended to report less burnout (Table 4). There was a positive trend in average PTA scores over time. The 2011 average PTA score was significantly higher than that in 2008 ( $p<0.001$, two independent samples two sided $t$-test), coinciding with introduction of the time-off policy. Finally, the 2013 PTA average score continued to increase relative to that in 2011. Table 5 presents the linear model analyses of PTA scores by gender and PGY. In 2008, the PTA scores of PGY1 was quite lower than all other trainees ( $p$-value $=0.072$ against $\mathrm{PGY} 2,0.061$ against $\mathrm{PGY} 3$, and $<0.001$ against PGY4+). However, in 2013, there were virtually no differences in the PTA scores among PGY1 through PGY3, while the difference with PGY4+ became notably smaller. 
Table 3 Subgroup analyses of satisfaction by gender or PGY

\begin{tabular}{|c|c|c|c|c|c|c|c|c|c|c|c|c|c|c|}
\hline & \multicolumn{2}{|l|}{2003} & \multicolumn{3}{|l|}{2005} & \multicolumn{3}{|l|}{2008} & \multicolumn{3}{|l|}{2011} & \multicolumn{3}{|l|}{2013} \\
\hline & Mean & SD & Mean & SD & $p$-value*,\# & Mean & SD & $p$-value*,\# & Mean & SD & $p$-value*,\# & Mean & SD & $p$-value ${ }^{*, \#}$ \\
\hline PGYI & 3.83 & 1.08 & 3.65 & 1.15 & 0.504 & 3.84 & 1.19 & 0.203 & 3.87 & 1.31 & 0.487 & 4.43 & 0.75 & 0.001 \\
\hline PGY2 & 3.65 & 1.21 & 3.72 & 1.20 & 0.954 & 3.62 & 1.19 & 0.901 & 3.80 & I.II & 0.258 & 4.27 & 0.75 & 0.001 \\
\hline PGY3 & 3.87 & 1.06 & 3.89 & 1.03 & 0.340 & 3.77 & 1.09 & 0.182 & 3.98 & 1.09 & 0.128 & 4.19 & 0.93 & 0.216 \\
\hline PGY4+ & 4.02 & 1.04 & 3.93 & 1.14 & 0.811 & 3.91 & 1.04 & 0.194 & 4.20 & 0.97 & 0.001 & 4.29 & 0.88 & 0.645 \\
\hline$p$-value* & 0.485 & & 0.267 & & & 0.057 & & & 0.003 & & & 0.392 & & \\
\hline Female & 3.72 & 1.12 & 3.80 & 1.14 & 0.406 & 3.64 & 1.10 & 0.430 & 3.91 & 1.12 & 0.028 & 4.28 & 0.84 & $<0.001$ \\
\hline Male & 3.96 & 1.07 & 3.80 & 1.14 & 0.489 & 3.91 & 1.13 & 0.361 & 4.13 & 1.04 & 0.132 & 4.32 & 0.84 & 0.064 \\
\hline$p$-value* & 0.039 & & 0.986 & & & 0.023 & & & 0.021 & & & 0.813 & & \\
\hline
\end{tabular}

Notes: *Chi-square test. $p$-values were computed by Monte Carlo simulations. Bold data indicates $<0.05$. ${ }^{\#}$-value against previous year survey.

Abbreviations: PGY, postgraduate training year; SD, standard deviation.

Table 4 Comparisons of career satisfaction and other key measures between residents with PTA scores above and below the median

\begin{tabular}{|c|c|c|c|c|c|c|c|c|c|}
\hline \multirow[t]{2}{*}{ Year } & \multirow[t]{2}{*}{ Mean } & \multirow[t]{2}{*}{ SD } & \multirow{2}{*}{$\begin{array}{l}p \text {-value against } \\
\text { previous year } \\
\text { survey }\end{array}$} & \multirow{2}{*}{$\begin{array}{l}\text { By PTA } \\
\text { scores }\end{array}$} & \multicolumn{2}{|c|}{ Lower score } & \multicolumn{2}{|c|}{ Higher score } & \multirow{2}{*}{$\begin{array}{l}\text { Lower vs } \\
\text { higher score } \\
p \text {-value }\end{array}$} \\
\hline & & & & & Mean & SD & Mean & SD & \\
\hline \multirow[t]{3}{*}{2008} & 2.70 & 0.57 & & Satisfaction & 3.53 & 1.18 & 4.00 & 1.08 & $<\left.0.00\right|^{b}$ \\
\hline & & & & Stress & 3.21 & 0.79 & 2.93 & 0.82 & $0.00 \mathrm{I}^{\mathrm{b}}$ \\
\hline & & & & Sleep & 3.27 & 0.60 & 3.44 & 0.61 & $0.004^{b}$ \\
\hline \multirow[t]{4}{*}{2011} & 2.88 & 0.60 & $<0.001$ & Satisfaction & 3.78 & 1.17 & 4.22 & 0.97 & $<0.00 \mathrm{I}^{\mathrm{b}}$ \\
\hline & & & & Stress & 3.33 & 0.84 & 2.93 & 0.72 & $<0.00 \mathrm{I}^{\mathrm{b}}$ \\
\hline & & & & Sleep & 3.27 & 0.62 & 3.58 & 0.56 & $<0.00 \mathrm{I}^{\mathrm{b}}$ \\
\hline & & & & Burnout & 2.66 & 0.80 & 2.08 & 0.59 & $<0.00 \mathrm{I}^{\mathrm{b}}$ \\
\hline \multirow[t]{7}{*}{2013} & 2.95 & 0.60 & 0.052 & Satisfaction & 4.15 & 0.88 & 4.43 & 0.78 & $0.00 \mathrm{I}^{\mathrm{b}}$ \\
\hline & & & & Stress & 3.26 & 0.87 & 2.78 & 0.88 & $<0.00 \mathrm{I}^{\mathrm{b}}$ \\
\hline & & & & Sleep & 3.30 & 0.56 & 3.65 & 0.56 & $<0.00 \mathrm{I}^{\mathrm{b}}$ \\
\hline & & & & Burnout & 2.47 & 0.80 & 2.01 & 0.68 & $<0.00 \mathrm{I}^{\mathrm{b}}$ \\
\hline & & & & masEE ${ }^{d}$ & 24.94 & 10.23 & 17.42 & 9.73 & $<0.00 I^{c}$ \\
\hline & & & & $\operatorname{mas} \mathrm{DP}^{\mathrm{d}}$ & 10.10 & 6.15 & 7.05 & 5.42 & $<0.00 \mathrm{I}^{\mathrm{c}}$ \\
\hline & & & & $\operatorname{masPA}^{d}$ & 39.32 & 6.09 & 40.75 & 5.33 & $0.010^{\circ}$ \\
\hline
\end{tabular}

Notes: ${ }^{a}$ Two independent sample two sided $t$-test; ${ }^{b}$ chi-square test ( $p$-values were computed by Monte Carlo simulations); ${ }^{c} W i l c o x o n$ test; ${ }^{d}$ Maslach Burnout Inventory summary scores for emotional exhaustion (masEE), depersonalization (masDP), and personal achievement (masPA). A higher PTA score implies that one can find more time to take care of personal needs. Bold data indicates $<0.05$.

Abbreviations: PTA, personal time availability; SD, standard deviation.

However, male trainees reported significantly higher PTA scores than female trainees in all years.

\section{Discussion}

This study provides a secondary data analysis for surveys of the entire GME cohort at five points in time: 2003, 2005, 2008, 2011, and 2013 and documents satisfaction trends from one institution. To our knowledge, there are no published reviews on longitudinal career satisfaction among GME trainees over a comparable time period. The results show continual improvement in overall career satisfaction. A control group for direct comparison was not available and after an intensive online search we could only find demographically similar data from Gallup survey data of US workers (January 2008 through April 2011). During the same time period as our study, Gallup survey data showed no improvement in job satisfaction. ${ }^{19}$ In addition, in our multivariate analysis, the improvement in satisfaction was still significant after adjusted for other demographics factors and our data reveal little consistent change in factors that are typically considered to have negative impact on job satisfaction, such as sleep deprivation or perception of stress and burnout.

Since this is a secondary data analysis of five crosssectional surveys, causality cannot be documented. We postulate, however, that the significantly higher satisfaction in career satisfaction documented in latter two surveys may be the synergistic result of two important institutional wellness initiatives detailed in the introduction (RWP and time-off policy), perhaps in conjunction with the duty hour change by ACGME in 2011. While utilization data are not shown, the number of residents who have used the RWP and requested 
Table 5 Linear model analyses of personal time availability (PTA) scores by sex and post graduate training year (PGY)

\begin{tabular}{|c|c|c|c|c|c|c|}
\hline Year & Variable & Value & Reference & Estimates & Standard error & $p$-value \\
\hline \multirow[t]{7}{*}{2008} & Intercept & & & 2.460 & 0.063 & $<0.001$ \\
\hline & Sex & Female & Reference & & & \\
\hline & & Male & & 0.157 & 0.053 & 0.003 \\
\hline & PGY & PGYI & Reference & & & \\
\hline & & PGY2 & & 0.141 & 0.078 & 0.072 \\
\hline & & PGY3 & & 0.150 & 0.080 & 0.061 \\
\hline & & PGY4+ & & 0.262 & 0.074 & $<0.001$ \\
\hline \multirow[t]{7}{*}{2011} & Intercept & & & 2.606 & 0.074 & $<0.001$ \\
\hline & Sex & Female & Reference & & & \\
\hline & & Male & & 0.279 & 0.051 & $<0.001$ \\
\hline & PGY & PGYI & Reference & & & \\
\hline & & PGY2 & & 0.070 & 0.088 & 0.428 \\
\hline & & PGY3 & & 0.146 & 0.088 & 0.100 \\
\hline & & PGY4+ & & 0.204 & 0.080 & 0.011 \\
\hline \multirow[t]{7}{*}{2013} & Intercept & & & 2.749 & 0.060 & $<0.001$ \\
\hline & Sex & Female & Reference & & & \\
\hline & & Male & & 0.236 & 0.051 & $<0.001$ \\
\hline & PGY & PGYI & Reference & & & \\
\hline & & PGY2 & & -0.014 & 0.078 & 0.857 \\
\hline & & PGY3 & & 0.037 & 0.080 & 0.643 \\
\hline & & PGY4+ & & 0.185 & 0.068 & 0.006 \\
\hline
\end{tabular}

Note: A higher PTA scores implies that one can find more time to take care of personal needs.

the time-off opportunity have trended up over the course of the study period. And we believe that higher rates of resident use of these interventions also partially explain improved career satisfaction.

Changes in ACGME requirements for residents' duty hours and responsibilities were also implemented during the study period. Current reports offer no consensus of a positive effect of changes in resident satisfaction. ${ }^{3,20-24}$ Also, from our data, it is unclear whether these changes caused the whole uptrend in resident career satisfaction. However, we think the institutional changes to promote resident access to mental health counseling and education regarding resilience and burnout, as well as employment of the time-off policy to address health care needs, implemented during this time frame had an impact on our trainees' career satisfaction at least in part.

The data regarding PTA scores are particularly notable and intriguing. Residents and fellows who found more time to take care of personal needs reported higher levels of career satisfaction, less perceived stress, and less burnout than others. Figure 1 shows the overall associations between the trends of PTA scores and other key measures. This important finding suggests that assuring residents have the time to address personal needs, through institutional policy and culture change, may improve their well-being and decrease burnout. In addition, it is interesting that the PTA scores of
PGY1 trainees seemed to be notably improved gradually with the time-off policy as shown in Table 5.

The changes in satisfaction during the time period were not homogeneous. Early in the study period, changes in a positive direction were experienced by more senior residents, while those for entry level residents remained relatively stable. During the latter part of the study (2011 and 2013), the most notable improvement occurred among the junior residents, while the senior residents' improvement plateaued. These findings suggest that both the wellness program and the time-off policy positively impacted trainees' satisfaction, but at different times. We hypothesize that the more senior residents, who were the first cohort to use and ultimately benefit from these institutional interventions, likely influenced their more junior colleagues to take advantage of those opportunities.

\section{Limitations}

There are limitations of this study. While results are from a single institution, we believe they are generalizable to training programs at similar-sized tertiary care academic health centers in the US. (The 2008 demographic data were not distinguishable from those of residents in other institutions in the US. ${ }^{2}$ ) The data reported in this study are a collection of five cross-sectional surveys (2003, 2005, 2008, 2011, and 2013). Since this is an observational study without a proper 
control group, rather than a traditional cohort or longitudinal study, the reported changes could be caused by other unobserved factors; thus, the reported associations cannot be interpreted as causative.

\section{Conclusion}

We recommend, in addition to continued assurance of duty hour compliance, that GME sponsoring institutions may consider programmatic enhancements such as the RWP and half-day off policy to promote a culture of self-care and wellness and improve career satisfaction among its trainees.

\section{Acknowledgments}

The authors would like to thank the residents of OHSU, especially those who participated in the surveys, and the OHSU GME Office for help in administering the surveys. This study was approved by the Institutional Review Board of OHSU (approval number 1711).

\section{Author contributions}

All authors contributed toward data analysis, drafting and critically revising the paper, gave final approval of the version to be published, and agree to be accountable for all aspects of the work.

\section{Disclosure}

The authors report no conflicts of interest in this work.

\section{References}

1. Eckleberry-Hunt J, Lick D, Boura J, et al. An exploratory study of resident burnout and wellness. Acad Med. 2009;84(2):269-277.

2. Eckleberry-Hunt J, Van Dyke A, Lick D, Tucciarone J. Changing the conversation from burnout to wellness: physician well-being in residency training programs. J Grad Med Educ. 2009;1(2):225-230.

3. Lefebvre DC. Perspective: resident physician wellness: a new hope. Acad Med. 2012;87(5):598-602.

4. Rosen IM, Christie JD, Bellini LM, Asch DA. Health and health care among housestaff in four U.S. internal medicine residency programs. J Gen Intern Med. 2000;15(2):116-121.

5. Girard DE, Sack RL, Reuler JB, Chang MK, Nardone DA. Survival of the medical internship. Forum Med. 1980;3(7):460-463.

6. Girard DE, Elliot DL, Hickam DH, et al. The internship - a prospective investigation of emotions and attitudes. West J Med. 1986;144(1):93-98.
7. Girard DE, Hickam DH. Predictors of clinical performance among internal medicine residents. J Gen Intern Med. 1991;6(2):150-154.

8. Girard DE, Hickam DH, Gordon GH, Robison RO. A prospective study of internal medicine residents' emotions and attitudes throughout their training. Acad Med. 1991;66(2):111-114.

9. Choi D, Dickey J, Wessel K, Girard DE. The impact of the implementation of work hour requirements on residents' career satisfaction, attitudes and emotions. BMC Med Educ. 2006;6:53.

10. Girard DE, Choi D, Dickey J, Dickerson D, Bloom JD. A comparison study of career satisfaction and emotional states between primary care and speciality residents. Med Educ. 2006;40(1):79-86.

11. Girard DE, Choi D, Dickey J, Wessel K, Austin D. A mid year comparison study of career satisfaction and emotional states between residents and faculty at one academic medical center. BMC Med Educ. 2006;6:36.

12. Cedfeldt AS, Bower EA, English C, Grady-Weliky TA, Girard DE, Choi D. Personal time off and residents' career satisfaction, attitudes and emotions. Med Educ. 2010;44(10):977-984.

13. Cedfeldt AS, Bower EA, Grady-Weliky TA, Flores C, Girard DE, Choi D. A comparison between physicians and demographically similar peers in accessing personal health care. Acad Med. 2012;87(3):327-331.

14. Cedfeldt A, Bower EA, Flores C, Brunett P, Choi D, Girard DE. Promoting resident wellness: evaluation of a time-off policy to increase residents' utilization of health care services. Acad Med. 2015;90(5):678-683.

15. Ey S, Moffit M, Kinzie JM, Choi D, Girard DE. "If you build it, they will come": attitudes of medical residents and fellows about seeking services in a resident wellness program. J Grad Med Educ. 2013;5(3): 486-492.

16. Rohland BM, Kruse GR, Rohrer JE. Validation of a single-item measure of burnout against the Maslach Burnout Inventory among physicians. Stress Health. 2004;20:75-79.

17. Maslach A, Jackson SE, Leiter MP. Maslach Burnout Inventory Manual. Palo Alto, CA: Consulting Psychologists Press; 1996.

18. R Development Core Team. R: A Language and Environment for Statistical Computing. Vienna, Austria: R Foundation for Statistical Computing; 2015.

19. Gallup. U.S. job satisfaction struggles to recover to 2008 levels; 2011. Available from: http://www.gallup.com/poll/147833/job-satisfactionstruggles-recover-2008-levels.aspx. Accessed March 5, 2015.

20. Landrigan CP, Rothschild JM, Cronin JW, et al. Effect of reducing interns' work hours on serious medical errors in intensive care units. $N$ Engl J Med. 2004;351(18):1838-1848.

21. Lockley SW, Cronin JW, Evans EE, et al. Effect of reducing interns' weekly work hours on sleep and attentional failures. $N$ Engl J Med. 2004;351(18):1829-1837.

22. Gopal R, Glasheen JJ, Miyoshi TJ, Prochazka AV. Burnout and internal medicine resident work-hour restrictions. Arch Intern Med. 2005;165(22):2595-2600.

23. Curet MJ. Resident work hour restrictions: where are we now? $J \mathrm{Am}$ Coll Surg. 2008;207(5):767-776.

24. Ahmed N, Devitt KS, Keshet I, et al. A systematic review of the effects of resident duty hour restrictions in surgery: impact on resident wellness, training, and patient outcomes. Ann Surg. 2014;259(6):1041-1053. 


\title{
Supplementary material
}

\author{
Resident/Fellow Questionnaire
}

$\mathbf{m m} / \mathbf{d d} / \mathbf{y y y y}$

The ACGME requires that the residents be asked about their training experiences. This questionnaire inquires about your career satisfaction, access to time off and emotional states; and as such, provides important information required by the ACGME and may be used for research purposes. This information will also be helpful as we optimize the training environment at OHSU. We request that you complete this short questionnaire. Anonymous results only will be known and used by the primary researchers, [list of investigators deleted for publication], and their support staff. No individual respondent will be identified nor contacted.

\section{Demographics:}

1. Gender: Male / Female

2. Year of Birth

3. PGY

PGY 1 / PGY 2 / PGY 3 / PGY 4 / PGY 5 / PGY 6 / PGY 7 / PGY 8 / PGY 9 / PGY

Ethnicity

4. Are you Hispanic or Latino? Yes / No

5. Race

1. White 2. Black or African American 3. Asian 4. American Indian or Alaska Native

6. Department or Division

7. AT THE PRESENT TIME, what do you think of your decision to become a physician?

- I am consistently pleased with my decision

- I am generally pleased although there are problems

- I am neither pleased nor displeased with the decision

- I have doubts but intend to stick it out

- I regret the decision and may drop out

(Questions 8-29 from Maslach Burnout Inventory are deleted per copyright. Please refer to http://www.mindgarden. com/117-maslach-burnout-inventory)

\section{Stress level of job}

30. Some jobs by their very nature are more stressful than others. How best would you judge the amount of stress in your particular job? Check the ONE statement that best describes how you feel.

- I feel much less stress in my residency/fellowship than I would expect it to generate

- I feel somewhat less stress in my residency/fellowship than I would expect it to generate

- I feel about as much stress in my residency/fellowship as I would expect it to generate

- I feel somewhat more stress in my residency/fellowship than I would expect it to generate

- I feel much more stress in my residency/fellowship than it should generate under normal conditions

\section{Level of burnout}

31. Please choose the closest description of your burnout status.

1) I enjoy my work. I have no symptoms of burnout.

2) Occasionally I am under stress, and I don't always have as much energy as I once did, but I don't feel burned out. 
3) I am definitely burning out and have one or more symptoms of burnout, such as physical and emotional exhaustion.

4) The symptoms of burnout that I'm experiencing won't go away. I think about frustration at work a lot.

5) I feel completely burned out and often wonder if I can go on. I am at the point where I may need some changes or may need to seek some sort of help.

32. How many hours of sleep did you get per night on average over the past one week period?

$\begin{array}{ccccc}<3 \text { hours } & 3-4 \text { hours } & 5-6 \text { hours } & 7-8 \text { hours } & >8 \text { hours } \\ 0 & 0 & 0 & 0 & 0\end{array}$

33. During the past 30 days, for about how many days have you felt you did not get enough rest or sleep? If none or don't know/not sure, write in "none" or "not sure".

$\begin{array}{lll}\circ \text { none } & \circ 10 & \circ 21 \\ \circ \text { not sure } & \circ 11 & \circ 22 \\ \circ 1 & \circ 12 & \circ 23 \\ \circ 2 & \circ 13 & \circ 24 \\ \circ 3 & \circ 14 & \circ 25 \\ \circ 4 & \circ 15 & \circ 26 \\ \circ 5 & \circ 16 & \circ 27 \\ \circ 6 & \circ 17 & \circ 28 \\ \circ 7 & \circ 18 & \circ 29 \\ \circ 8 & \circ 19 & \circ 30 \\ \circ 9 & \circ 20 & \circ 31\end{array}$

Questions for Personal Time (time taken outside of work to meet personal needs, aside from vacation or family/medical leave time):

Residents/Fellows:

34. Are you aware of the existence of a policy for allowing residents to take personal time?
a. Yes
b. No
c. I don't know

35. Does your program track personal time?
a. Yes
b. No
c. I don't know

36. Does your program track reasons for personal time?
a. Yes
b. No
c. I don't know

37. What reasons for personal time are acceptable to your program? (choose all that apply)
a. Medical appointments for myself and/or family
b. Dental appointments for myself and/or family
c. Mental health appointments for myself and/or family 
d. Other (please explain)

e. My program does not ask for a reason, all reasons are accepted

38. What reasons for personal time are acceptable to your program, if other:

\section{Questions for Health}

39. Would you say that in general your health is:
(1) Excellent
(2) Very good
(3) Fair
(4) Poor

40. I have a dentist.
a. Yes
b. No

41. How long has it been since you last visited a dentist or dental clinic for any reason? Include visits to dental specialists, such as orthodontists.
a. Within the past year (anytime less than 12 months ago)
b. Within the past 2 years ( 1 year but less than 2 years ago)
c. Within the past 5 years ( 2 years but less than 5 years ago)
d. 5 or more years ago

42. How long has it been since you had your teeth cleaned by a dentist or dental hygienist?
a. Within the past year (anytime less than 12 months ago)
b. Within the past 2 years ( 1 year but less than 2 years ago)
c. Within the past 5 years ( 2 years but less than 5 years ago)
d. 5 or more years ago

43. I am able to see a dentist for visits other than routine checkups.
a. Yes
b. No
c. N/A

44. I have a primary care physician.
a. Yes
b. No

45. I have been to see a primary care physician or ob/gyn for a routine checkup within the last:
a. Within the past year (anytime less than 12 months ago)
b. Within the past 2 years ( 1 year but less than 2 years ago)
c. Within the past 5 years ( 2 years but less than 5 years ago)
d. 5 or more years ago
e. Don't know/Not sure
f. Never 
46. I am able to see a primary care physician or ob/gyn for visits other than routine checkups:
a. Yes
b. No
c. N/A

47. I have a physical health need for which I need to see a health care professional, but have not scheduled an appointment.
a. Yes
b. No

48. If yes to the previous question, how long have you had the health need?
a. For the past year (anytime less than 12 months ago)
b. For the past 2 years ( 1 year but less than 2 years ago)
c. For the past 5 years ( 2 years but less than 5 years ago)
d. 5 or more years

49. What are the reasons you have not scheduled an appointment? (check all that apply)
a. I do not believe my physical health need is significant enough to take time away from work.
b. I am pressured by my program not to take time off from work
c. I have enough free time outside working hours
d. It is considered a "badge of honor" to not take time off from work
e. The timing of my work schedule makes it impossible to schedule appointments in advance (i.e. no way to predict free time)
f. I do not want to add to the workload of my colleagues
g. There is no mechanism to request time off
h. It has not been a priority
i. Other (please explain)

50. What are the reasons you have not scheduled an appointment, if other:

Questions for Life:

51. I am able to find time for the following personal needs: (Please mark the appropriate frequency)

\begin{tabular}{|l|l|l|l|l|}
\hline & $\begin{array}{c}\text { As often as } \\
\text { I need to }\end{array}$ & $\begin{array}{c}\text { Somewhat less often } \\
\text { than I need to }\end{array}$ & $\begin{array}{c}\text { Much less often } \\
\text { than I need to }\end{array}$ & Never \\
\hline Haircut & & & & \\
\hline Family events & & & & \\
\hline Home care (chores, maintenance, etc.) & & & & \\
\hline Grocery shopping & & & & \\
\hline Adequate sleep & & & & \\
\hline Pick up dry cleaning & & & & \\
\hline Pick up package & & & & \\
\hline Connecting with partner and/or friends & & & & \\
\hline Other - please explain & & & & \\
\hline
\end{tabular}


52. During the past month, other than your regular job, did you participate in any physical activities or exercises such as running, calisthenics, golf, gardening or walking for exercise?
a. Yes
b. No
c.Don't know/not sure

53. Aside from health care needs, I have other unmet personal needs to which I need to attend.
a. Yes
b. No

54. If so, what is your unmet need?

55. If yes to question $\# 52$, how long have you had the personal need?
a. For the past year (anytime less than 12 months ago)
b. For the past 2 years ( 1 year but less than 2 years ago)
c. For the past 5 years ( 2 years but less than 5 years ago)
d. 5 or more years

56. What are the reasons you have been unable to take care of this unmet personal need? (check all that apply)
a. I do not believe my personal need is significant enough to take time away from work.
b. I am pressured by my program not to take time off from work
c. I have enough free time outside working hours
d. It is considered a "badge of honor" to not take time off from work
e. My work schedule makes it impossible to predict free time in advance
f. I do not want to add to the workload of my colleagues
g. There is no mechanism to request time off
h. Other (please explain)

57. What are the reasons you have not scheduled time off, if other:

Appendix S1 2013 Survey Instrument.

Abbreviations: ACGME, Accreditation Council of Graduate Medical Education; dd, day; mm, month; OHSU, Oregon Health \& Science University; PGY, postgraduate training years; yyyy, year.

\section{Publish your work in this journal}

Advances in Medical Education and Practice is an international, peerreviewed, open access journal that aims to present and publish research on Medical Education covering medical, dental, nursing and allied health care professional education. The journal covers undergraduate education, postgraduate training and continuing medical education including emerging trends and innovative models linking education, research, and health care services. The manuscript management system is completely online and includes a very quick and fair peer-review system. Visit http://www.dovepress.com/testimonials.php to read real quotes from published authors. 